\title{
Application of a rotatable orthogonal central composite design to the optimization of the formulation and utilization of an useful plasticizer for cement
}

\author{
A. Kamoun, B. Samet, J. Bouaziz and M. Châabouni* \\ Laboratoire de Chimie Industrielle, École Nationale d'Ingénieurs, BP. W, 3038 Sfax, Tunisie
}

\begin{abstract}
Black liquor (BL), a by-product of Alfa pulping industry, is mixed with small amounts of sulfonated naphthalene formaldehyde polymer (SNF) to give a useful cement dispersant having a durable action. In order to check the effect of three variables (the ratio water/cement, \% black liquor, \% SNF) on two properties of the cement grout (cement plasticity and cement plasticity loss), a rotatable orthogonal central composite design is set up. It is concluded from response surface and isoresponse curve studies that the level of plasticity is governed by the percentage of SNF while its durability is ensured by the percentage of the black liquor.
\end{abstract}

Key words. Cement - plasticizer - black liquor - workability - experimental design.

\section{Introduction}

To improve the performances of concrete, several admixtures have been introduced to the concrete industry. Some of them modify the rheological behavior of cement grouts, mortars and fresh concretes [1]. Such admixtures, referred to as "plasticizers" or "water-reducers", are employed to obtain a homogeneous concrete with high workability for easy handling, placing, compaction, and production of high strength concrete. They permit the use of less water to obtain the same slump (a measure of consistency or workability) or, equivalently, the attainment of a higher slump at a given water content; they also use less portland cement to realize the same compressive strength [2].

Moreover, in the early seventies, new types of synthetic molecules, extremely effective in controlling the workability of concrete were introduced in the cement industry. These products are categorized as superplasticizers, high range water reducers (HRWR), or fluidifiers. Most of these products are composed of sulfonated melamine formaldehyde condensate (SMF), sulfonated naphthalene formaldehyde condensate (SNF), or modified lignosulfonate (MLS).

A number of mechanisms have been proposed to account for the dispersive effect of the admixture. The most important postulates that the active matter of the admixture which has the structure of both surfactants and organic polymers, is adsorbed on the surface of the cement particles and imparts them repelling charges. This results, first, in liberating the water that would have been entrapped by cement agglomerates, so that it can contribute to the fluidity of the concrete, and second, in making additional surfaces of the cement particles available for early hydration.

A preliminary study allowed us to show that the application of SNF all alone as superplasticizer presents two major drawbacks, namely its high cost and its very brief action. On the other hand, we showed that the combination of SNF with black liquor (BL), a by-product of Alfa pulping industry substantially increases the duration of the plasticizing effect. The performances of the two-component admixture depend closely on their ratio and on the total amount of the admixture added to the concrete or the cement grout.

The aim of the present study is to search, by the means of the response surface methodology [4-9], for the best formulation and utilization of the two-component admixture to be used as a superplasticizer for cement grouts. A rotatable orthogonal central composite design [10-11] is set up to check the effect of three variables: the ratio water/cement, $\% \mathrm{BL}$ and, \% SNF on two properties of the cement grout: cement plasticity and cement plasticity loss.

\section{Raw materials and experimental techniques}

\section{Raw materials}

- Sulfonated naphthalene and formaldehyde condensate: a brown powder, containing $87 \%$ active matter, manufactured by Vanderbilt - USA.

- Black liquor: residuary water from the Alfa pulping industry supplied by "Société Nationale de Cellulose et Papier

* Correspondence and reprints.

Received March 03, 1998; revised January 27, 1999; accepted February 08, 1999. 


\section{Original articles}

Alfa" (SNCPA) - Tunisia. It essentially contains: lignin, reducing sugars, organic salts, mineral salts and free soda.

- Cement: the mineralogical composition of the cement is $\mathrm{C}_{3} \mathrm{~S}=48.73 \% ; \mathrm{C}_{2} \mathrm{~S}=26.39 \% ; \mathrm{C}_{3} \mathrm{~A}=9.53 \% ; \mathrm{C}_{4} \mathrm{AF}=$ $10.34 \%$ and, $\mathrm{CaSO}_{4}=5.01 \%$.

\section{Experimental techniques}

This study is based on the evaluation of loss of workability (slump-loss) of cement grouts with time, using a miniature slump test [12]. This test, carried out with a mini-cone [1213], is very similar to the familiar concrete slump test using Abrams cone, only the dimensions of the cone are changed, the proportions remain the same (Fig. 1).

- Mixture preparation: pastes are prepared by introducing $400 \mathrm{~g}$ of cement into the water within 10 seconds, manual mixing for 50 seconds, and, additionally mixing at a high speed with a hand-held mixer for one minute. The superplasticizer (SNF) powder is slurried into the black liquor and post-added to the wetted-cement. The samples are then mixed for two more minutes and the paste fluidity is measured by the mini-slump test at 10 and, 120 minutes from the start of the cement mixing.

- Plasticity measurement: the experiment consists of introducing the mixture of cement, water and admixture, in the mini cone placed on a horizontal plate and to lift the mini cone with a rapid motion to drop the paste. The spread of the paste is, then, measured; the results are given as the average of the diameter spread measured on two perpendicular diameters.

The plasticity of the cement grout decreases with time due to the hydration phenomenon of the cement constituents and hence the spread of the paste also decreases with time.

\section{Experimental methodology}

Optimization of the formulation and utilization of the novel composite admixture is achieved by using the response surface methodology. A rotatable orthogonal central composite design is used to study the empirical relationships between two properties of the admixture and three controlled factors. This part of the paper briefly discusses the principles governing the construction and analysis of this type of experimental design. Some data are oversimplified and a few statements are probably not too rigidly in accordance with the strictest details of mathematical statistics. These liberties have been taken to present a condensation of an extremely large mass of highly technical material into as brief a space as possible.

\section{Mathematical model}

The mathematical model of a three variable central composite design can be represented as follows $[4,14]$ :

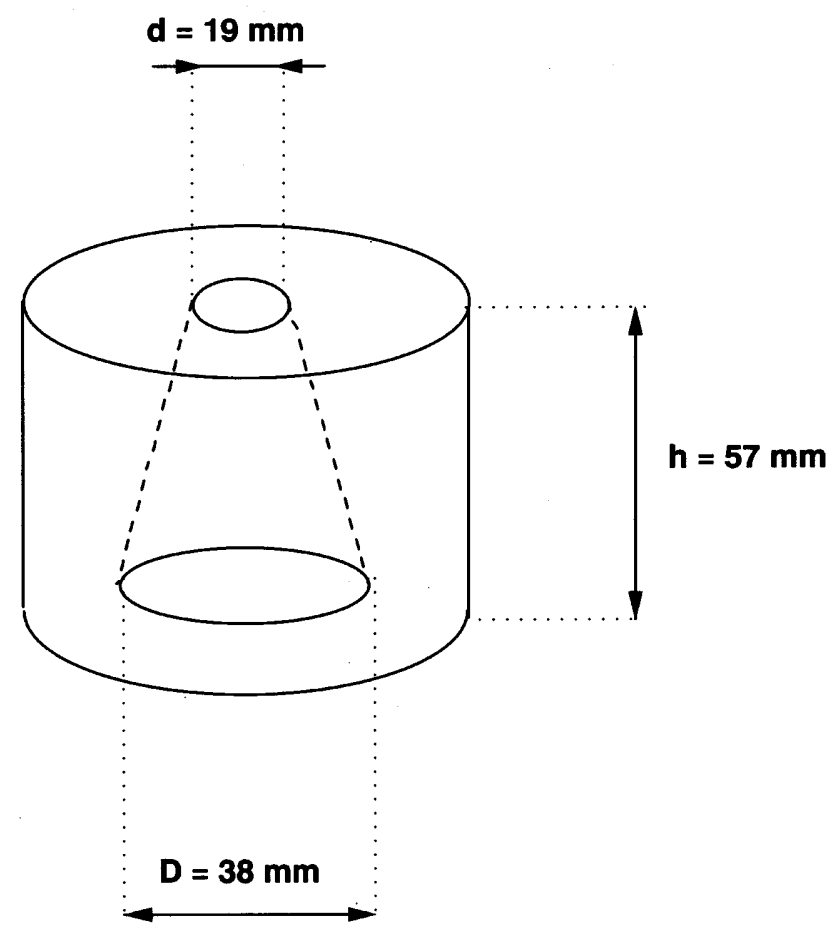

Fig. 1. Miniature slump cone.

$$
\begin{gathered}
\eta=\beta_{0}+\beta_{1} X_{1}+\beta_{2} X_{2}+\beta_{3} X_{3}+\beta_{12} X_{1} X_{2} \\
+\beta_{13} X_{1} X_{3}+\beta_{23} X_{2} X_{3}+\beta_{11} X_{1}^{2}+\beta_{22} X_{2}^{2}+\beta_{33} X_{3}^{2}
\end{gathered}
$$

where,

$\eta$ : theoretical response function;

$X_{j}$ : coded variables of the system;

$\beta_{0}, \beta_{j}, \beta_{j k}$ and, $\beta_{j j}$ : true model coefficients.

The observed response $y_{i}$ for the $i^{\text {th }}$ experiment is:

$$
y_{i}=\eta_{i}+e_{i} \quad\left(e_{i} \text { : error }\right) \text {. }
$$

The model coefficients $\beta_{0}, \beta_{1}, \ldots$ and, $\beta_{33}$ are estimated by a least squares fitting of the model to the experimental results obtained in the design points. For the estimated values of these coefficients, the symbols $b_{0}, b_{1}, \ldots$ and, $b_{33}$ will be used. The computed values of the responses are designated by $\hat{y}_{i}$.

\section{The central composite design [8,9,11]}

23 experiments are used to estimate the model coefficients. The graphical representation of the distribution of these experimental points is given in figure 2. The corresponding three-variable central composite design is shown in table I.

The 23 experiments can be divided into three groups as follows:

$-N_{\mathrm{F}}=2^{3}$ factorial experiments carried out at the corners of the cube; 
Table I. Central composite orthogonal rotatable design for three variables.

\begin{tabular}{lccc}
\hline$N_{i}$ & $X_{1}$ & $X_{2}$ & $X_{3}$ \\
\hline 1 & -1 & -1 & -1 \\
2 & +1 & -1 & -1 \\
3 & -1 & +1 & -1 \\
4 & +1 & +1 & -1 \\
5 & -1 & -1 & +1 \\
6 & +1 & -1 & +1 \\
7 & -1 & +1 & +1 \\
8 & +1 & +1 & +1 \\
9 & -1.6818 & 0 & 0 \\
10 & +1.6818 & 0 & 0 \\
11 & 0 & -1.6818 & 0 \\
12 & 0 & +1.6818 & 0 \\
13 & 0 & 0 & -1.6818 \\
14 & 0 & 0 & +1.6818 \\
15 & 0 & 0 & 0 \\
16 & 0 & 0 & 0 \\
17 & 0 & 0 & 0 \\
18 & 0 & 0 & 0 \\
19 & 0 & 0 & 0 \\
20 & 0 & 0 & 0 \\
21 & 0 & 0 & 0 \\
22 & 0 & 0 & 0 \\
23 & 0 & 0 & 0 \\
\hline
\end{tabular}

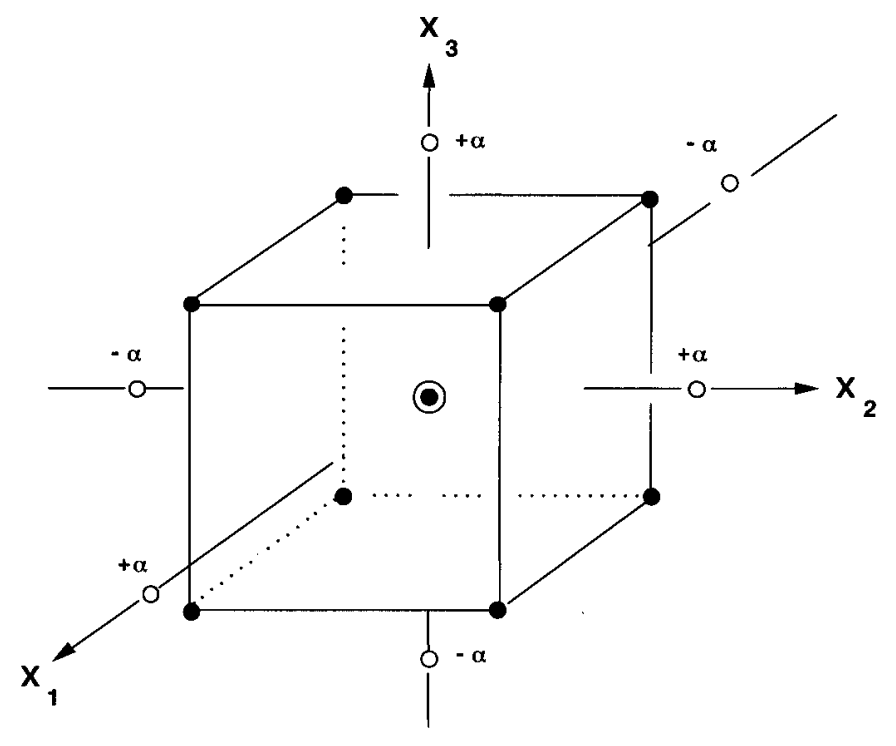

Fig. 2. Distribution of the experimental points in a three variable central composite design.
$-N_{\mathrm{a}}=2 \times 3$ axial experiments carried out on the axes at a distance of $\pm \alpha$ from the center. The distance $\alpha$ is calculated so as to obtain rotatability. A three variable central composite design is rotatable if:

$$
\alpha= \pm\left(N_{\mathrm{F}}\right)^{1 / 4}= \pm 1.6818
$$

- $N_{0}$ experiments carried out at the center of the experimental domain. In our case, the $N_{0}$ value is fixed at 9 so as to obtain orthogonality and isovariance by rotation properties. The experiments repeated at the center of the domain (15 to 23 in Tab. I) permit to calculate an independent estimation of the "pure" experimental error variance [9].

\section{Validation of the model}

In the case of a composite design, the validation of the model is carried out by an appropriate analysis of variance (ANOVA). The method can be described as follows $[9,11]$ :

- the total sum of squares $S S_{\mathrm{T}}$ (with 22 degrees of freedom) is divided into the sum of squares $S S_{\mathrm{X}}$ due to regression (with 9 degrees of freedom) and the residual sum of squares $S S_{\mathrm{R}}$ (with 13 degrees of freedom):

$$
\begin{gathered}
S S_{\mathrm{T}}=S S_{\mathrm{X}}+S S_{\mathrm{R}} \\
\sum_{i}\left(y_{i}-\bar{y}\right)^{2}=\sum_{i}\left(\hat{y}_{i}-\bar{y}\right)^{2}+\sum_{i}\left(y_{i}-\hat{y}_{i}\right)^{2}
\end{gathered}
$$

- the residual sum of squares $\left(S S_{\mathrm{R}}\right)$, can be partitioned into two parts; the first part is due to "pure" experimental error $\left(S S_{\mathrm{E}}\right)$, and is computed as the sum of squared deviations in the center point experiments calculated with $9-1=8$ degrees of freedom, the second part $\left(S S_{\mathrm{L}}\right)$ which relates to the "lack of fit" can be used to assess the significance of the model. $S S_{\mathrm{L}}$ is determined with $13-8=5$ degrees of freedom.

- the fitted model is considered adequate if the variance due to the lack of fit is not significantly different from the pure error variance.

\section{Results and discussion}

\section{Experimental data}

In order to define the experimental domain explored, the level values of variables are chosen in such a way that limits are as wide as possible while all the experiments are feasible. Table II shows the levels attributed to each variable.

Two responses are studied:

- " $y$ ": the plasticity value, measured at 10 minutes from the start of the cement mixing (in mm of spreading);

- " $V$ ': the mean rate of plasticity loss during the first 110 minutes $(\mathrm{mm} / \mathrm{min})$. 


\section{Original articles}

Table II. Variables and experimental domain.

\begin{tabular}{lccccc}
\hline Variables & \multicolumn{5}{c}{ Levels } \\
& -1.68 & -1 & 0 & +1 & +1.68 \\
\hline$x_{1}:$ water/cement $(\mathrm{g} / \mathrm{g})$ & 0.323 & 0.330 & 0.340 & 0.350 & 0.357 \\
$x_{2}: \%$ black liquor & 0.100 & 0.120 & 0.150 & 0.180 & 0.200 \\
$x_{3}: \% \mathrm{SNF}$ & 0.066 & 0.080 & 0.100 & 0.120 & 0.134 \\
\hline
\end{tabular}

The admixture concentration are expressed as percentages added on the cement basis.

Table III. Experimental design in natural variables and responses measured.

\begin{tabular}{lccccc}
\hline$N_{i}$ & $E$ & $L$ & $D$ & $y$ & $100 \mathrm{~V}$ \\
\hline 1 & 0.330 & 0.120 & 0.080 & 109.5 & 44.27 \\
2 & 0.350 & 0.120 & 0.080 & 120.0 & 45.45 \\
3 & 0.330 & 0.180 & 0.080 & 110.5 & 31.36 \\
4 & 0.350 & 0.180 & 0.080 & 124.0 & 34.55 \\
5 & 0.330 & 0.120 & 0.120 & 117.0 & 42.73 \\
6 & 0.350 & 0.120 & 0.120 & 130.0 & 45.00 \\
7 & 0.330 & 0.180 & 0.120 & 121.0 & 28.18 \\
8 & 0.350 & 0.180 & 0.120 & 132.0 & 26.36 \\
9 & 0.323 & 0.150 & 0.100 & 109.5 & 40.00 \\
10 & 0.357 & 0.150 & 0.100 & 132.0 & 41.82 \\
11 & 0.340 & 0.100 & 0.100 & 120.0 & 50.00 \\
12 & 0.340 & 0.200 & 0.100 & 121.0 & 28.18 \\
13 & 0.340 & 0.150 & 0.066 & 115.0 & 40.00 \\
14 & 0.340 & 0.150 & 0.134 & 127.0 & 40.91 \\
15 & 0.340 & 0.150 & 0.100 & 117.0 & 40.00 \\
16 & 0.340 & 0.150 & 0.100 & 117.0 & 40.45 \\
17 & 0.340 & 0.150 & 0.100 & 115.0 & 35.45 \\
18 & 0.340 & 0.150 & 0.100 & 116.0 & 37.27 \\
19 & 0.340 & 0.150 & 0.100 & 117.0 & 39.09 \\
20 & 0.340 & 0.150 & 0.100 & 117.0 & 40.90 \\
21 & 0.340 & 0.150 & 0.100 & 115.0 & 37.27 \\
22 & 0.340 & 0.150 & 0.100 & 117.0 & 38.18 \\
23 & 0.340 & 0.150 & 0.100 & 116.0 & 36.36 \\
\hline & & & & &
\end{tabular}

Table III shows the experimental design in natural variables and the obtained response values of $y$ and $V$ for the 23 experiments.

\section{Estimated models}

The 23 observed responses are used to compute the model coefficients using the least square method $[8,9,11,15]$. This allows us to write the two resulting estimated models:

$$
\begin{gathered}
\hat{y}=116.34+6.29 X_{1}+0.93 X_{2}+4.11 X_{3} \\
+1.45 X_{1}^{2}+1.37 X_{2}^{2}+1.54 X_{3}^{2}+0.13 X_{1} X_{2} \\
+0 X_{1} X_{3}+0.13 X_{2} X_{3}
\end{gathered}
$$

Table IV. ANOVA for the validation of the plasticity model.

\begin{tabular}{lccccc}
\hline Sources of variation & $S S$ & $d d l$ & m.s & Fexp & test $F^{*}$ \\
\hline Regression & 883.7 & 9 & 98.19 & 66.34 & H.S \\
Residual & 18.3 & 13 & 1.41 & & \\
$\quad$ - Lack of fit & $(12.3)$ & $(5)$ & 2.46 & 3.28 & N.S \\
$\quad$ - Pure error & $(6.0)$ & $(8)$ & 0.75 & & \\
Total variation & 902.0 & 22 & & & \\
\hline
\end{tabular}

*H.S.: significant at the level $99 \% ; F_{0.01}(9,13)=4.19$.

N.S. non significant at the level $95 \% ; F_{0.05}(5,8)=3.69$.

Table V. ANOVA for the validation of the mean rate of plasticity loss model.

\begin{tabular}{lccccc}
\hline Sources of variation & $S S$ & $d d l$ & $m . s$ & Fexp & test $F *$ \\
\hline Regression & 674.6 & 9 & 74.95 & 12.72 & H.S \\
Residual & 76.6 & 13 & 5.89 & & \\
$\quad$ - Lack of fit & $(47.7)$ & $(5)$ & 9.54 & 2.64 & N.S \\
$\quad$ - Pure error & $(28.9)$ & $(8)$ & 3.61 & & \\
Total variation & 751.3 & 22 & & & \\
\hline
\end{tabular}

*H.S.: significant at the level $99 \% ; F_{0.01}(9,13)=4.19$.

N.S. non significant at the level $95 \% ; F_{0.05}(5,8)=3.69$.

$$
\begin{gathered}
100 \hat{V}=38.39+0.58 X_{1}-6.86 X_{2}-0.87 X_{3} \\
+0.28 X_{1}^{2}-0.36 X_{2}^{2}+0.12 X_{3}^{2}-0.26 X_{1} X_{2} \\
-0.49 X_{1} X_{3}-1.17 X_{2} X_{3} .
\end{gathered}
$$

\section{Analysis of variance and validation of the models}

Analysis of variance is carried out as described above. Results of this analysis are summarized in tables IV and V which show that the lack of fit is not significant for the two models. We can, then, conclude that the obtained second order models adequately approximate the true surfaces.

Moreover it appears that all the main effects of the three variables and their quadratic terms are significant (99\% probability level) in the plasticity model $(\hat{y})$ while only the main effect of black liquor is significant in the plasticity loss rate model $(\hat{V})$. This allows us to simplify the latter model as follows:

$$
100 \hat{V}=38.48-6.86 X_{2}
$$

\section{Interpretation of the response surface models}

The relationship between the responses and the experimental variables can be illustrated graphically by plotting the response values versus the levels of variables taken two at a time. The topography of these response surfaces also can be 


\section{Original articles}

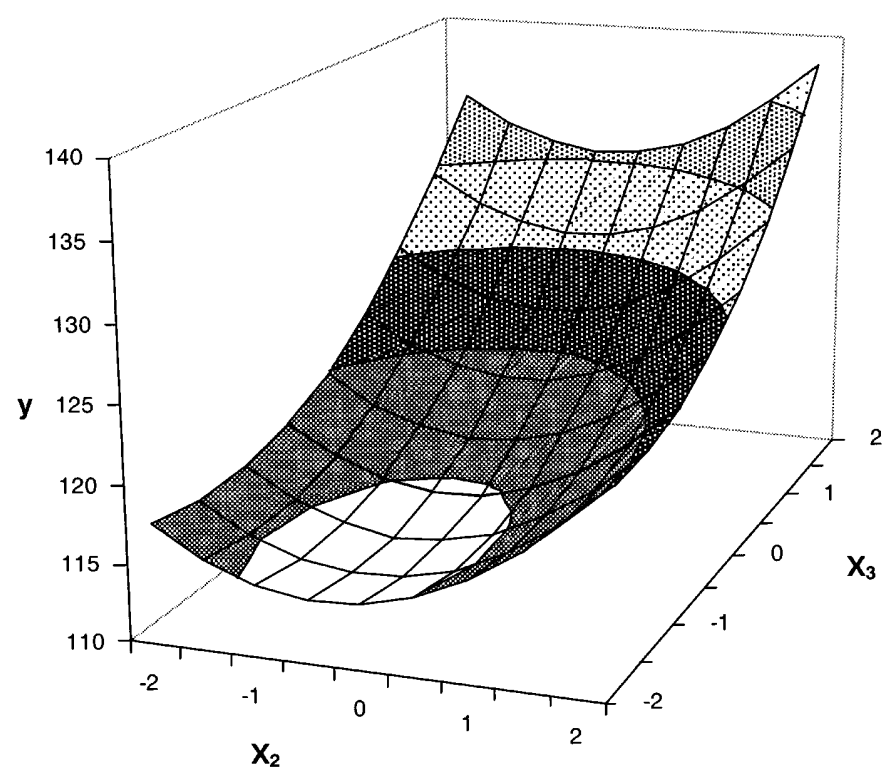

Fig. 3. Three-dimensional cement plasticity response surface with $X_{1}=0$ ( $y$ : plasticity; $X_{2}: \% \mathrm{BL} ; X_{3}: \% \mathrm{SNF}$ ).

illustrated by isoresponse contour lines which represent lines of constant response represented on a two variable plane. Such plots are helpful in studying the effects of the variation of the factors in the domain studied and consequently, in determining the optimal experimental conditions.

Response surfaces and isoresponse curves, obtained for the plasticity, with $X_{1}$ fixed at zero are shown in figures 3 and 4.

From examining these figures, we note that plasticity $(\hat{y})$ increases essentially when the amount of plasticizer SNF increases. This increase is more sensitive to changes in \% of SNF than to those of BL. Indeed the effect of $\%$ of BL is weak and depends on the \% of SNF: for the \% of SNF inferior to 0.10 , an increase of the $\%$ of BL from 0.15 to 0.20 increases the plasticity. For the \% of SNF superior to 0.10 the $\%$ of BL has not any effect. The contour plots in figure 4 show that the high plasticity of cement pastes can be obtained through the addition of high doses of SNF, whatever the quantity of BL may be. These curves also show that high plasticity can be obtained through the use of large quantities of black liquor, the disadvantage of this approach is that it significantly would raise the amount of air entrained and, thereby decreases the density and the strength of the hardened cement grout [1].

Concerning the cement plasticity loss, looking at the equation (8) $\left(100 \hat{V}=38.48-6.86 X_{2}\right)$, we see that an increase of the $\%$ of BL from 0.10 to 0.20 allows an appreciable decrease of the response.

In practice, high plasticity of the cement grout can be ensured by addition of the superplasticizer, while the

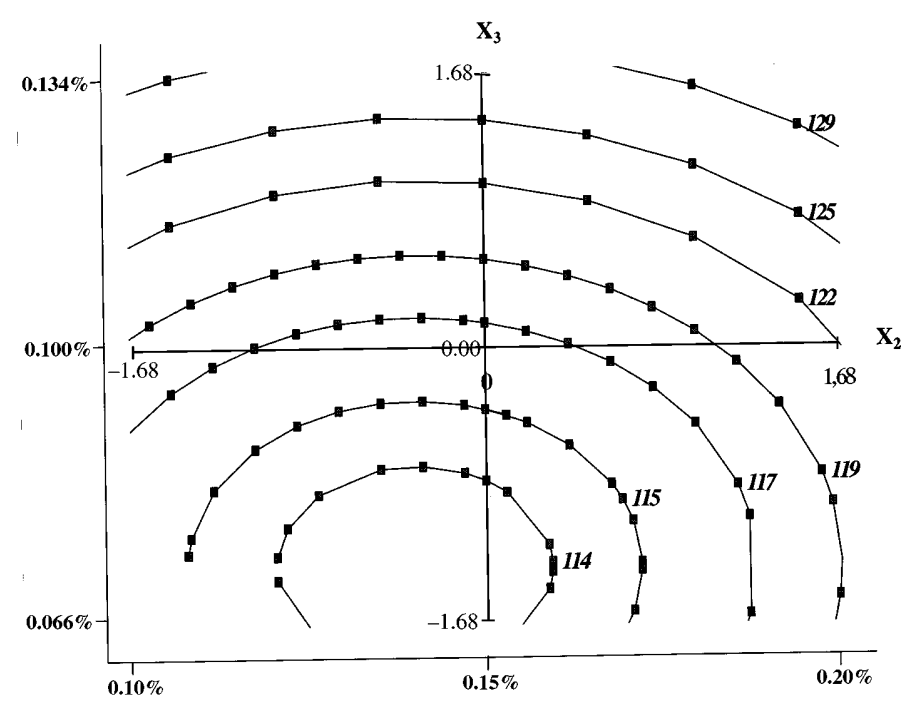

Fig. 4. Isocontours of the cement plasticity with $X_{1}=0\left(X_{2}: \% \mathrm{BL}\right.$; $\left.X_{3}: \% \mathrm{SNF}\right)$.

upholding of this plasticity is only ensured by the use of high amounts of black liquor.

To further analyze the experimental results, we represent isoresponse curves of the plasticity when $X_{3}$ (Fig. 5) or $X_{2}$ (Fig. 6) is fixed at its mean level.

Figure 5 shows that high increase in the plasticity can be obtained only by increasing the ratio of water to cement. The influence of small variations of the $\%$ of BL on the plasticity is negligible.

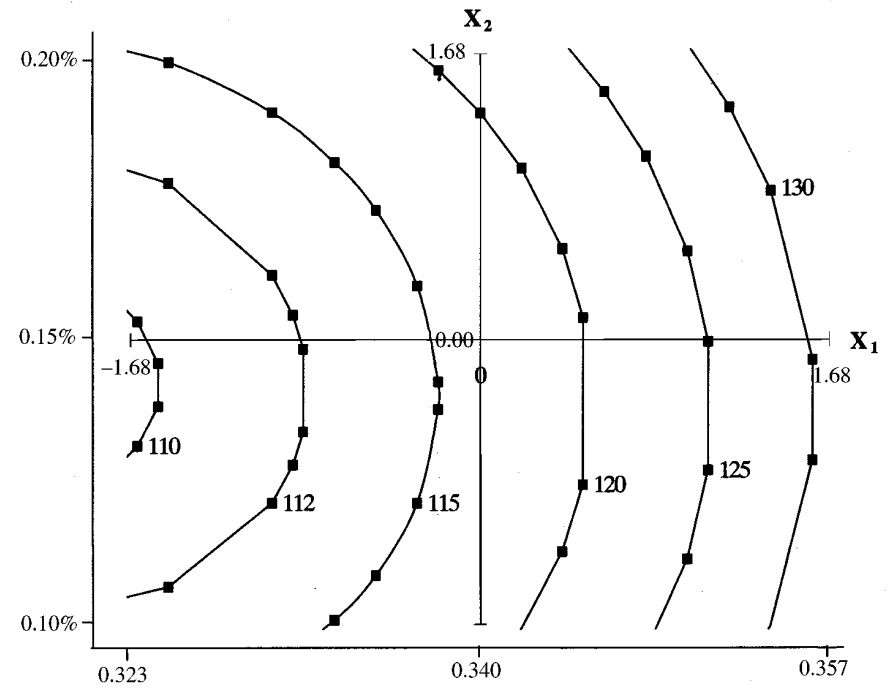

Fig. 5. Isocontours of the cement plasticity with $X_{3}=0\left(X_{1}\right.$ : water/cement; $X_{2}: \% \mathrm{BL}$ ). 


\section{Original articles}

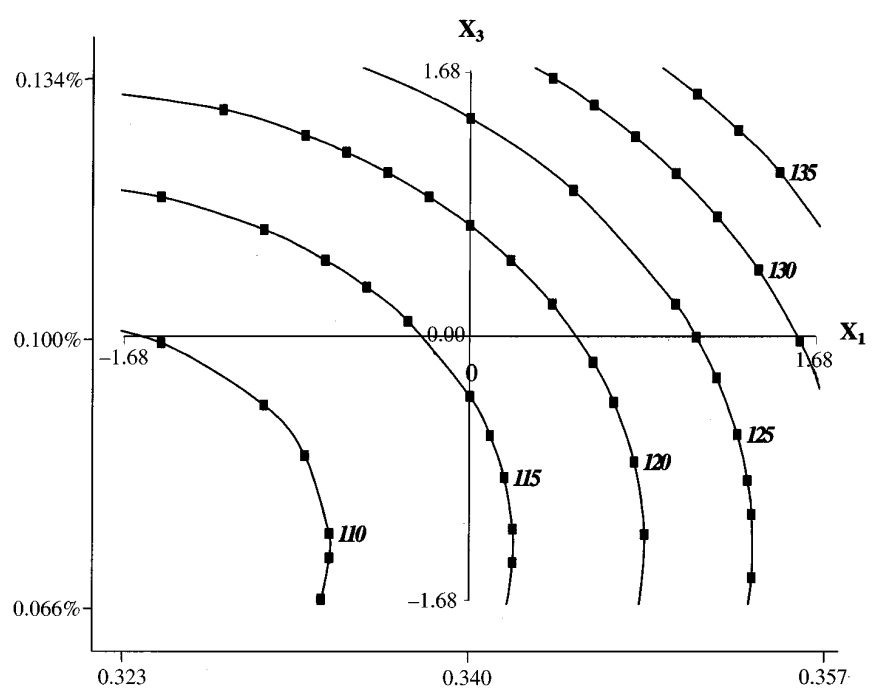

Fig. 6. Isocontours of the cement plasticity with $X_{2}=0\left(X_{1}\right.$ : water/cement; $X_{3}$ : \% SNF).

Figure 6 clearly shows that the more the ratio of water to cement and the \% of SNF increase, the more the plasticity increases.

\section{Conclusion}

This study permitted us to conceive an original composite plasticizer for cement grout by mixing sulfonated naphthalene formaldehyde polymer with black liquor. This admixture ensures both high plasticity and durable action.

Optimization of the formulation and the utilization of the novel admixture is achieved by setting up a rotatable orthogonal central composite design which leads to two main results; first, the properties of the cement grouts namely "plasticity" and "plasticity loss" can be controlled through the choice of percentage of sulfonated naphthalene formaldehyde polymer and black liquor. Second, the level of plasticity is governed by the percentage of sulfonated naphthalene formaldehyde polymer while its durability is ensured by the percentage of black liquor.

\section{Acknowledgements}

The authors gratefully acknowledge the Tunisian "Direction Générale de la Recherche Scientifique et Technologique" for its financial support and the "Société Nationale de Cellulose et Papier Alfa" for supplying black liquor used in this study.

\section{References}

1. Venuat, M. In: Adjuvants et traitement des ouvrages en bétons, Venuat Ed., 1984.

2. Dodson, D. In: Concrete admixtures, Van Nostrand Reinhold Ed., New York 1990.

3. Aïtcin, P. C.; Jolicoeur, C.; MacGregor, J. G. A.C.I. Concrete Internat. 1994, 16(5), 45-52.

4. Box, E. P.; Hunter, W. G.; Hunter, J. S. Statistics for experimenters, J. Wiley Ed., New York 1978.

5. Mathieu, D.; Phan Tan Luu, R. Méthodologie de la recherche expérimentale, récents progrès en génie des procédés, Stratégie expérimentale et procédés biotechnologiques, Lavoisier Tech. Doc. Ed., Paris, 1995; 9, pp 1-10.

6. Feinberg, M.; Wirth, P. Analusis 1984, 12(10) 490-495.

7. Goupy, J. L.; Sjogren, C. E.; Seip, K. L. Analusis, 1990, 18, 524-530.

8. Montgomery, D. C. Design and analysis of experiments, J. Wiley Ed., New York, 1991.

9. Carlson, R. Design and optimization in organic synthesis, Elsevier Ed., 1992.

10. Chaair, H.; Heughebaert, J. C.; Heughebaert, M.; Vaillant, $M$. J. Mater. Chem. 1994, 4(5), 765-770.

11. Mathieu, D.; Phan Tan Luu, R. Approche méthodologique des surfaces de réponses, Journées d'études en statistiques, C.I.R.M., Marseille (France), 14-18 Octobre 1996.

12. Kantro, D. L. Cem. Concr. Aggregates 1980, 95-102.

13. Ramachandran, V. S. il Cemento, 1989, 83-88.

14. Sado, G.; Sado, M. C. In: Les plans d'expériences: de l'expérimentation à l'assurance qualité, Afnor Ed., 1991.

15. Feki, M.; Chaabouni, M.; Ayedi, H. F.; Heughebaert, J.C.; Vaillant, M., Can. J. Chem. Eng., 1987, 65, 132-136. 